\title{
Aerobic capacity and respiratory patterns are better in recreational basketball-engaged university students than age-matched untrained males
}

\author{
Mladen Mikić1,2, Marko D.M. Stojanović1,2, Aleksandra Milovančev ${ }^{3,4}$, Tatjana Miljković ${ }^{3,4}$, \\ Marija Bjelobrk ${ }^{3,4}$, Miodrag Golubović ${ }^{3,4}$, Nebojša Maksimović ${ }^{1}$, Antonino Bianco ${ }^{5}$, Patrik Drid ${ }^{1}$ \\ ${ }^{1}$ Faculty of Sport and Physical Education, University of Novi Sad, Novi Sad, Serbia; ${ }^{2}$ Advanced Rehab \& Conditioning \\ Lab, Faculty of Sport and Physical Education, University of Novi Sad, Novi Sad, Serbia; ${ }^{3}$ Faculty of Medicine, University of \\ Novi Sad, Novi Sad, Serbia; ${ }^{4}$ Institute of Cardiovascular Diseases of Vojvodina, Sremska Kamenica, Serbia; ${ }^{5}$ Department \\ of Psychology, Educational Science and Human Movement, University of Palermo, Palermo, Italy
}

\begin{abstract}
Study aim: To asses and compare the aerobic capacity and respiratory parameters in recreational basketball-engaged university students with age-matched untrained young adults.

Material and methods: A total of 30 subjects were selected to took part in the study based on recreational-basketball activity level and were assigned to a basketball (BG: $\mathrm{n}=15$, age $22.86 \pm 1.35$ yrs., body height $185.07 \pm 5.95 \mathrm{~cm}$, body weight $81.21 \pm 6.15 \mathrm{~kg}$ ) and untrained group (UG: $\mathrm{n}=15$, age $22.60 \pm 1.50 \mathrm{yrs}$, body height $181.53 \pm 6.11 \mathrm{~cm}$, body weight $76.89 \pm 7.30 \mathrm{~kg}$ ). Inspiratory vital capacity (IVC), forced expiration volume (FEV1), FEV1/IVC ratio, maximal oxygen consumption $\left(\mathrm{VO}_{2 \max }\right)$, ventilatory threshold $\left(\mathrm{VO}_{2} \mathrm{VT}\right.$ ) and time to exhaustion, were measured in all subjects. Student T-test for independent Sample and Cohen's $d$ as the measure of the effect size were calculated.

Results: Recreational basketball-engaged students (EG) reached significantly greater IVC $(\mathrm{t}=7.240, \mathrm{p}<0.001, \mathrm{~d}=1.854)$, FEV1 $(\mathrm{t}=10.852, \mathrm{p}<0.001, \mathrm{~d}=2.834)$, FEV1/IVC ratio $(\mathrm{t}=6.370, \mathrm{p}<0.001, \mathrm{~d}=3.920)$, maximal oxygen consumption $(\mathrm{t}=9.039, \mathrm{p}<0.001, \mathrm{~d}=3.310)$, ventilatory threshold $(\mathrm{t}=9.859, \mathrm{p}<0.001, \mathrm{~d}=3.607)$ and time to exhaustion $(\mathrm{t}=12.361$, $\mathrm{p}<0.001, \mathrm{~d}=4.515)$ compared to $\mathrm{UG}$.

Conclusions: Long-term exposure to recreational basketball leads to adaptive changes in aerobic and respiratory parameters in male university students.
\end{abstract}

\section{Keywords: Spirometry - Maximal oxygen consumption - Team-sport - Recreational basketball}

\section{Introduction}

A number of epidemiological and clinical research in last decades have been using lung function parameters as health indicators, with many studies showing the association of hindered respiratory function with mortality risk, and cardiorespiratory outcomes and health related quality of life $[22,26,30]$. In addition, it has been recently proved that even slight lung function abnormalities, within reference values, are correlated with similar decreases in various health outcomes [15]. Hindered respiratory function is associated with diminished ventilation and aerobic capacity and reported to affect many other physiological processes in the body [33]. While the key factors and biological background of this downregulated lung parameters remain to be elucidated, a number of population-based investigations recently indicate that a substantial percentage of the general adult population is characterized with hindered lung function parameters, distinguished by diminished both forced expiratory volume in $1 \mathrm{~s}\left(\mathrm{FEV}_{1}\right)$ vital capacity (IVC) levels [22, 42].

Maximal oxygen uptake $\left(\mathrm{VO}_{2 \max }\right)$, the highest amount of oxygen utilization during large muscle groups nearmaximal load, for decades has been considered criterion measure for aerobic capacity. It has been correlated with enhanced cardiac-events risk [38], with low $\mathrm{Vo}_{2 \max }$ repeatedly reported as a substantial risk factor for diseases as 
malignancy and diabetes [37]. Finally, hindered $\mathrm{VO}_{2 \max }$ is independently related to several-fold increases in cardiovascular diseases [3] or all-cause mortality [53, 63]. There is a growing recognition of the value of anaerobic threshold (onset of ventilation nonlinear increase during incremental exercise) as another reliable index of aerobic capacity, with oxygen uptake at anaerobic threshold found to reflect the ability to sustain prolonged submaximal exercise better than maximal oxygen uptake [7]. Previous studies have found that oxygen uptake at anaerobic threshold was inversely associated with hypertension, cardiovascular, and all-cause mortality in adults [34, 35], suggesting its use as health-related index.

With a purpose to establish efficient preventive strategies for lung disease and health risks related to low aerobic capacity, elucidating parameters that influence lung function and aerobic capacity is of great importance. The proofs are emerging relating respiratory parameters level to distinct lifestyle characteristics like physical activity and physical fitness [24, 45], with even low-intensity exercise in the general population found to impact respiratory indices leading to higher FEV1 and IVC [19]. In addition, exercise has been known for decades as a potent toll for aerobic fitness improvements, with high - intensity intermittent exercise likely superior than traditional endurance training [39]. While high - intensity intermittent exercise can be applied through running, swimming, biking etc., this specific type of exercise can also be obtained through sport games-related training sessions. Indeed, participation in basketball-related activities has been reported to produce high-intensity interval physiological response with concomitant positive changes in motivation and an increased frequency of social interactions, contributing to high adherence rate and maintenance of an active lifestyle [10]. Consequently, basketball could be look upon as a potential solution to improve respiratory patterns and aerobic endurance [28].

Investigations have proved that intermittent high-intensity exercise $[28,43,46,68]$ and long-term moderateintensity exercise $[25,28]$ induce inspiratory muscles fatigue, consequently leading to adaptation and increased performance of taxed systems. Basketball is recognized as an intermittent, high-intensity sport with numerous multidirectional high intensity movement performed at a different pace. In addition, basketball players were found to cover around 5000-6000 $\mathrm{m}$ during game playing time [61], implying that both the aerobic and anaerobic energy provision pathways are heavily taxed [52]. Indeed, during basketball related activities (training and games), participants frequently reach submaximal and near-maximal levels of both oxygen consumption and ventilation [54]. Top and regional-level basketball is saturated with frequent movement pattern and intensity changes [1], both shown to reach high levels of heart rates (HRs) [11, 47]. Recreational basketball, characterized by $3-5$ players per side playing half court all full court and with significantly less formal structure and games rules enforcement (playing time; three, eight and twenty-four second rules etc.) has also been proved to be highly intensive. Indeed, both half court and full court recreational basketball are characterized by an intermittent activity profile with high mean heart rate (over $80 \%$ of $\mathrm{Hr}_{\text {max }}$ ) and are bioenergetically enabled through largescale utilization of anaerobic and aerobic metabolism pathways [57, 62]. Significant improvements in broadspectrum health benefits including cardiopulmonary fitness are likely outcome.

Sports science aspects of college, professional and youth basketball has been subjected to significant scientific attention in the past [72]. Interestingly, recreational basketball, with its theoretically well-grounded healthenhancing context has been addressed scarcely, with hardly any information available related to recreational basketball played by young male individuals. University student population is especially interesting in this context, as it has been shown that enrolling university is strong determinant of steep decline in physical activity and physical fitness $[36,60]$, with consequently increased health risks. Furthermore, basketball is frequently a preferred type of physical activity for university students, associated with improved social and psychological health [2]. However, it remains elusive if basketball game activities on a regular bases per se, without incorporating other training stimuluses regularly seen in basketball clubs and basketball academies (strength $\&$ conditioning practices, individual practices etc.), could improve various health outcomes.

For all we know, few studies elaborated the topic $(62,31)$ with just one study examined full court recreational basketball training and health outcomes and found that three months of training improved overall health profile including maximum oxygen uptake and physical strain during submaximal exercise in untrained men [57]. Further investigations seem warranted. Based on the aforementioned, it is reasonable to assume that long-term practicing basketball-game activities could extensively stress cardiorespiratory system inducing increased strength and/or endurance or changes in its structural properties.

This research aim was to asses and compare the aerobic capacity and respiratory parameters in recreational basketball engaged students with age-matched untrained young healthy adults. We hypothesized that long term recreational basketball practice would be reflected with higher aerobic endurance and respiratory parameters in engaged students than sedentary age-matched controls. 


\section{Materials and methods}

\section{Participants}

This study presents a cross-sectional design with a single measurement in two groups. One hundred and twenty male participants were recruited for the study, with sixty recreational basketball-engaged and sixty untrained students (University of Novi Sad). The recreational basketball-engaged students were recruited through the University Sport Association of Novi Sad. Concisely, association forwarded a public call for our study and obliged all teams in University basketball league to participate (nine teams in total). In addition, first 60 players with online signed preliminary consent form were selected to participate in introductory lecture. An introductory lecture was organized at association facility, with benefits of physical activity for health in general, study objectives and measurements procedures presented to potential study-participants. Also, they were introduced to inclusion criteria for the study, which had to be met: 1. Participating in recreational basketball (Faculty's teams participating in university league organized by university student association) for at least 2 years; 2. Not participating in any form of organized training and competition previously; 3 . Involved exclusively in 2-3 full court basketball training sessions per week (75-90 min per session), including weekend game (one referee, $4 * 12$ minutes without stopping clock while the play is not active); 4. Apparently healthy - not suffering from any acute or chronic disease. Forty-five interested were excluded based on inclusion criteria, with 15 left allocated to basketball group (BG: $\mathrm{n}=15$, age $22.86 \pm 1.35$ yrs., body height $185.07 \pm 5.95 \mathrm{~cm}$, body weight $81.21 \pm 6.15 \mathrm{~kg}$ ).

Sixty untrained students were recruited through University of Novi Sad Student association. Concisely, university students were approached face-to-face, by social media (Instagram, Facebook) or telephone and were invited for an introductory lecture. In addition, first 60 students with online signed preliminary consent form were selected for an introductory lecture. It was organized in an amphitheater at the Faculty of Sport and Physical Education, University of Novi Sad, explaining student's lifestyle health issues in general. In addition, sedentary behavior and physical fitness and their relation with myriad of adverse health effects was underlined. Finally, participants were invited to enroll the study, but only those which met inclusion criteria of being nonsmokers, sedentary in previous 24 months at least and had not participated in organized sport training previously in life. Twenty-five participants met inclusion criteria, and 15 of them were randomly selected and allocated to untrained group (CG: $\mathrm{n}=15$, age $22.60 \pm 1.50$ yrs., body height $181.53 \pm 6.11 \mathrm{~cm}$, body weight $76.89 \pm 7.30 \mathrm{~kg}$ )
A questionnaire related to history of injuries was completed by each participant prior to selection of eligible individuals for the sample. All participants provided a signed informed consent (participants' anonymity and confidentiality was assured). The study was conducted according to the Helsinki declaration and ethical approval was obtained from ethics committee of University of Novi Sad, Serbia (Ref. No. 44-01-02/2018-1). Students received an academic reward for having participated in the study.

\section{Measurements protocol}

To evaluate the potential cardiovascular and lung patterns adaptations induced by regular recreational basketball activity, participants attended early-morning (7.00-9.00) respiratory and cardiopulmonary testing session respectively, after an overnight fast $(>8 \mathrm{~h})$ and without any strenuous exercise 2 days preceding testing. All measurements were performed in a laboratory setting with the same instruments and techniques. Standard environmental conditions $\left(18-22^{\circ} \mathrm{C}, 760 \mathrm{mmHg}\right.$ and $30-60 \%$ for temperature, atmospheric pressure and relative humidity, respectively) were provided for every testing procedure. Before commencing the testing, weight and height were determined for each participant.

\section{Anthropometric parameters}

Body weight measurements were performed using Omron weight scale BF511 (Omron, Japan) to the nearest $0.1 \mathrm{~kg}$. Body height was measured to the nearest $0.1 \mathrm{~cm}$ using a Martin anthropometer (GPM, Switzerland). Body Mass Index was calculated by dividing the weight in kilograms $(\mathrm{kg})$ with the height in meters $(\mathrm{m})$ squared $\left(\mathrm{kg} / \mathrm{m}^{2}\right)$. All anthropometric parameters were obtained by the same person.

\section{Respiratory (pulmonary) functions}

Inspiratory vital capacitiy (IVC) and forced expiration volume (FEV1) were measured using SPIROLAB III (Medical International Research, Rome, Italy) spirometry. Participants were instructed to inhale the maximum volume of air from the point of maximum expiration for IVC assessment. For FEV1 assessment subjects were instructed to forcibly exhale the air in one second following maximal inhalation. Participants were asked to sit upright in the chair with the feet positioned firmly on the ground. During the test, the assessor put the clip on subject's nose to ensure that the expiration and inspiration is performed solely using mouth. Testing procedure consisted of 3 attempts and the best result achieved out of 3 trials was recorded. Between the two maneuvers, 30s rest was inserted in order to prevent bronchoconstriction. Participants were advised not to eat $2 \mathrm{~h}$ prior to spirometry assessment in order to obtain high validity of testing results. 


\section{Maximal oxygen consumption and Ventilatory threshold}

$\mathrm{VO}_{2 \max }$ and ventilatory threshold $\left(\mathrm{VO}_{2}\right.$ at ventilatory threshold) values were obtained by performing cardiopulmonary exercise testing (CPET) on a motorized treadmill (t-170, Cosmed, Italy). We used mixing chamber gas analyzer and breath by breath analysis technique (Quark CPET system manufactured by Cosmed) for determination of maximal oxygen consumption. Heart rate monitor (COSMED Wireless HR Monitor) was also used. The gas analyzer was calibrated with reference gas calibration and volume transducer was calibrated using a 3-L syringe, both according to producer instructions and before each test.

Three minutes at $8 \mathrm{~km} / \mathrm{h}$ were allowed for warm up purposes and after that, incremental load of $0.5 \mathrm{~km} / \mathrm{h}$ every 30 seconds with $1 \%$ inclination was applied until volitional fatigue. Maximal oxygen consumption (defined as the average of the two highest single consecutive 20 -s $\mathrm{VO}_{2}$ mean values attained toward the end of the test) was recorded. The criteria for attaining maximal oxygen consumption included two of the following: volitional exhaustion; respiratory exchange ratio equal or greater than 1.10; reaching above $90 \%$ of the age predicted $\mathrm{HR}_{\max }$ (220-age); and oxygen uptake remained stable even with an increase in intensity [21]. In addition, time to exhaustion (defined as a total time elapsed from the first increase in load above $8 \mathrm{~km} / \mathrm{h}$ until the end of the test) and ventilatory threshold (defined as a second disproportionate increase of the volume of carbon dioxide expired in relation to the volume of oxygen consumption) [70] were obtained.

\section{Statistical analysis}

Data was presented as mean and standard deviation. Statistical analysis was performed using SPSS for Windows, Version 20.0 (IBM Corp. 20, Armonk, NY). Considering all data were normally distributed, two sample T-test was used. Cohen's $d$ as the measure of the effect size of the mean difference was calculated. A Cohen's of 0.00-0.19, $0.20-0.49,0.50-0.79$ and $\geq 0.80$ was considered as trivial, small, moderate, and large, respectively [12]. Two-sided $\mathrm{p}<0.05$ was considered statistically significant.

Table 1. Descriptive statistics of participants

\begin{tabular}{lcccc}
\hline Variables & Basketball $(\mathrm{n}=15)$ & Untrained $(\mathrm{n}=15)$ & $\mathrm{t}$ & $\mathrm{p}$ \\
\hline Body height $[\mathrm{cm}]$ & $185.07 \pm 5.95$ & $181.53 \pm 6.11$ & 1.603 & 0.120 \\
Body weight $[\mathrm{kg}]$ & $76.89 \pm 7.30$ & $76.12 \pm 6.49$ & 0.306 & 0.762 \\
Age $[\mathrm{yrs}]$ & $22.86 \pm 1.35$ & $22.60 \pm 1.50$ & 0.510 & 0.614 \\
BMI $\left[\mathrm{kg} / \mathrm{m}^{2}\right]$ & $22.40 \pm 1.04$ & $23.10 \pm 1.66$ & -1.377 & 0.179 \\
\hline
\end{tabular}

${ }^{1}$ Data are presented as mean \pm standard deviation; BMI - body mass index.

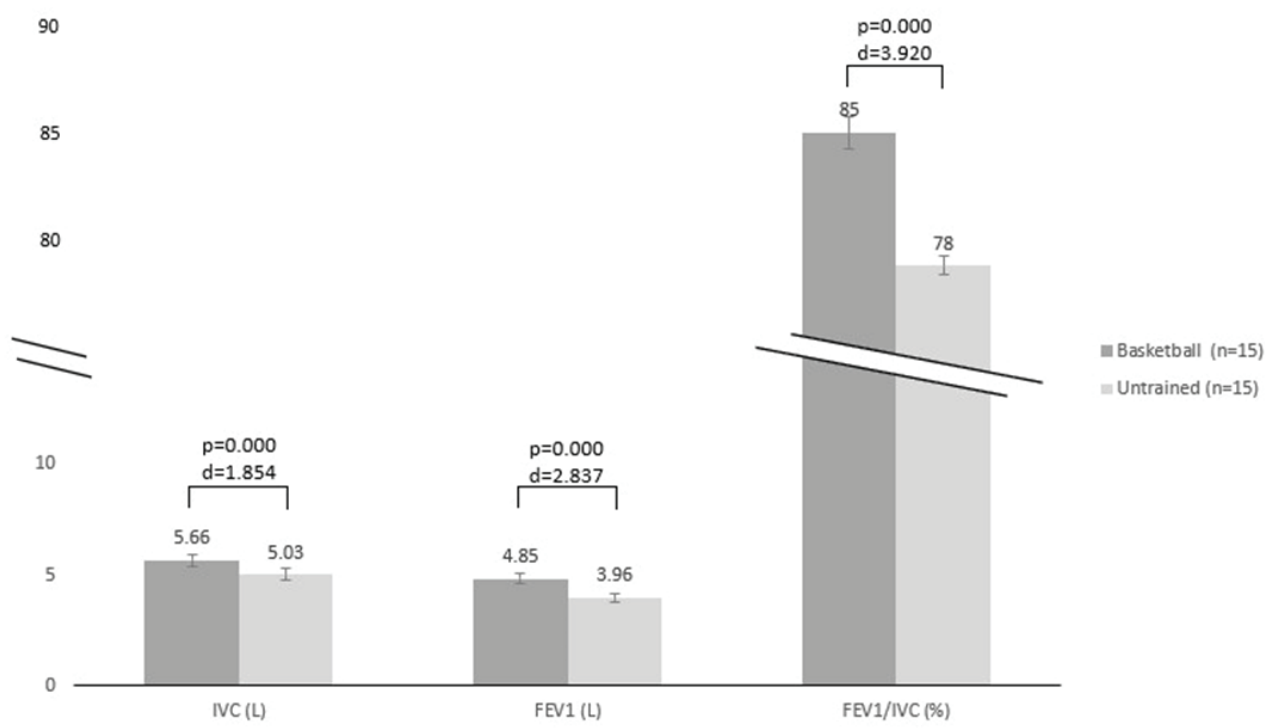

Figure 1. Respiratory parameters for basketball and untrained groups: IVC - inspiratory vital capacity; FEV1 - forced expiration volume; FEV1/IVC- forced expiratory volume in $1 \mathrm{~s}$ (FEV1)/ Inspiratory vital capacity (IVC) ratio 


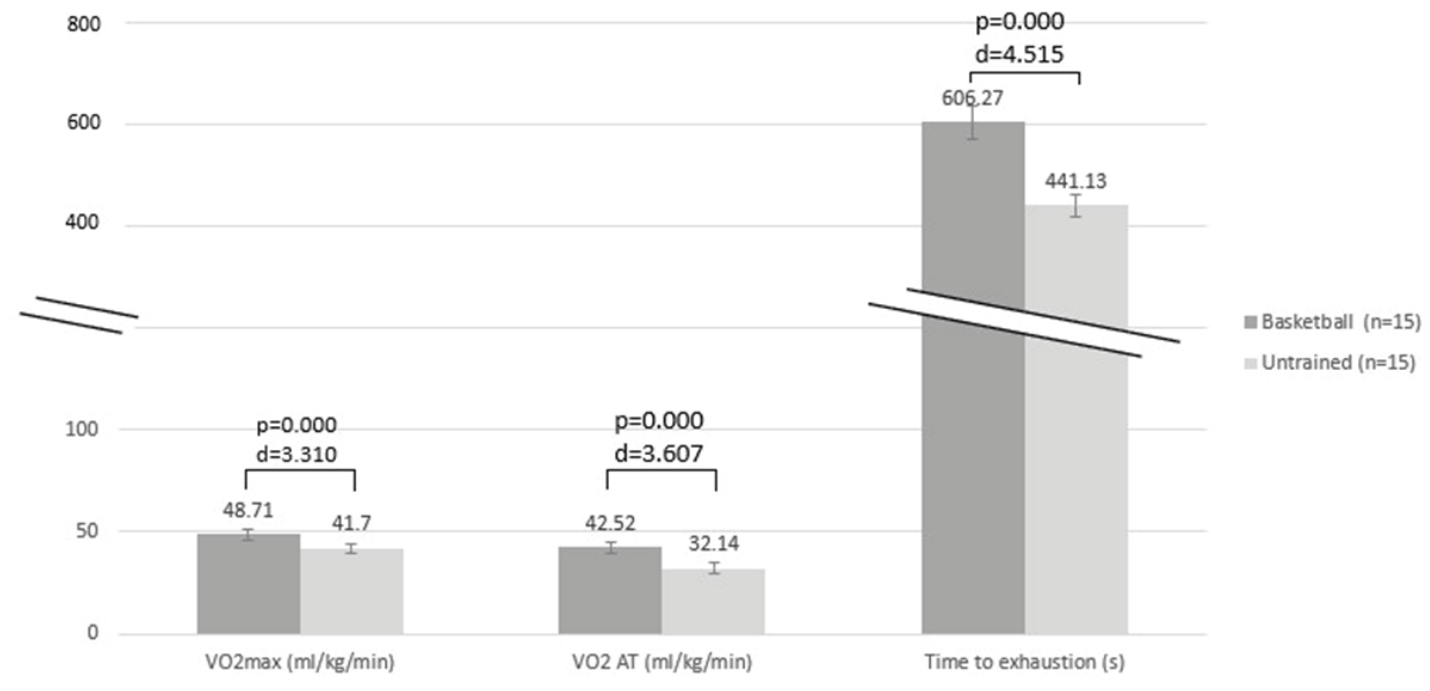

Figure 2. Aerobic fitness parameters for basketball and untrained groups: $\mathrm{VO}_{2 \max }$ - maximal oxygen uptake; $\mathrm{VO}_{2} \mathrm{AT}-$ oxygen uptake at anaerobic threshold; Time to Exhaustion - total time of the test

\section{Results}

Anthropometric characteristics of the participants are presented as mean \pm SD (table 1). Non - significant difference in age, body weight, body mass index (BMI) and body height between groups ( $p>0.05)$ was recorded.

Recreational basketball players (BG) reached significantly greater IVC values than the untrained $(p=0.001)$, with large effect size $(d=1.854)$. Additionally, BG demonstrated significantly higher FEV1 values $(\mathrm{p}<0.001)$ with large effect size $(d=2.837)$ compared to unrained. Moreover, FEV1/IVC ratio was significantly $(p<0.001)$ higher with large effect size $(d=3.920)$ in $B G$ compared to the UG (Figure 1).

BG attained higher maximal oxygen consumption values in comparison to untrained ( $\mathrm{p}<0.001)$, with large effect size $(d=3.310)$. Moreover, ventilatory threshold $\left(\mathrm{VO}_{2} \mathrm{AT}\right)$ significantly differ among the investigated groups $(p<0.001)$, with large effect size $(d=3.607)$. Finally, time to exhaustion was significantly higher in BG than in the untrained group $(\mathrm{p}<0.001)$, with large effect size $(d=4.515)$ (Figure 2).

\section{Discussion}

It is well recognized that continuous exercise participation can substantially improve one's health-outcomes and that monitored exercise programs may effectively be utilized for prevention and treatment of lifestyle diseases. In addition, traditional exercise prescription and implementation are frequently shown to produce high dropout rate [49] with new lifestyle diseases-strategies needed. These strategies should be aimed to identify programs with long-lasting participant motivation, enabling them to prevail active and consequently produce a worthwhile lifestyle change with extended physiological adaptations. The major outcomes of our study were that young male adults engaged in long term recreational-basketball poses significantly higher aerobic capacity indices, maximal oxygen uptake and ventilatory threshold than age-matched sedentary controls. In addition, significantly higher time to exhaustion reported indicate increased physical performance of subjects in basketball group. Furthermore, they also exhibit better inspiratory vital capacity (IVC), forced expiratory volume in 1s (FEV1) and FEV1/IVC ratio than sedentary counterparts. Previously, it has been reported that recreational basketball can improve maximum oxygen uptake in both untrained young females [18] and male university students [56]. In line with these findings, we showed that male adults recreationally engaged in basketball activity solely, poses significantly higher levels of aerobic capacity but also respiratory patterns than sedentary counterparts and consequently better health profile.

Maximal oxygen consumption found in our study was $\sim 49 \mathrm{ml} \cdot \mathrm{kg}^{-1} \cdot \mathrm{min}^{-1}$ and $\sim 42 \mathrm{ml} \cdot \mathrm{kg}^{-1} \cdot \mathrm{min}^{-1}$ for basketball and untrained group, respectively. A large Norwegian study [40] investigated maximal oxygen consumption in various age groups and reported values of around $54 \mathrm{ml} \cdot \mathrm{kg}^{-1} \cdot \mathrm{min}^{-1}$ in 20 to 29 years men, while other studies revealed maximal oxygen uptake values more in line with our study findings. For example, mean maximal oxygen uptake was estimated at $44.5 \mathrm{ml} \cdot \mathrm{kg}^{-1} \cdot \mathrm{min}^{-1}$ for US men 20-29 years of age [69], while another study [29] reported average maximal oxygen consumption of 
$48 \mathrm{ml} \cdot \mathrm{kg}^{-1} \cdot \mathrm{min}^{-1}$ in $20-29$ years old cohort. Finally, average $\mathrm{VO}_{2 \max }$ of $42.3 \mathrm{ml} \cdot \mathrm{kg}^{-1} \cdot \mathrm{min}^{-1}$ in 20-29 years old Korean men, similar to our study findings for controls, was recently reported [69]. Noteworthy, maximal oxygen consumption was estimated and not directly measured, which could bias this study findings. Thus, our untrained group had below average values for corresponding population worldwide, troublesome fact considering reduced $\mathrm{VO}_{2 \max }$ are regularly being related to increased cardiovascular and all-cause mortality risk. On the other hand, the basketball group showed significantly better $\mathrm{VO}_{2 \max }$ than the untrained group, with results in line or close to one's highest average recorded worldwide. It has been previously reported that $3.5 \mathrm{ml} \cdot \mathrm{kg}^{-1} \cdot \mathrm{min}^{-1}$ improvements correlates with $13 \%$ reductions in all-cause mortality and $15 \%$ reductions in CVD/coronary heart disease [32]. In addition, each $5 \mathrm{ml} \cdot \mathrm{kg}^{-1} \cdot \mathrm{min}^{-1}$ improvements were found to decrease odds of cardiovascular risk factor clustering for $56 \%$ [5]. Ventilatory threshold has been used in sport science for decades to optimize training intensity, monitor training progress and as the best physiological predictor of endurance running performance $[7,55]$. However, studies relating ventilatory threshold and various health outcomes are scarce, most frequently this parameter being used to clinically assess patient physiological function/dysfunction: heart failure, diabetes, peripheral artery disease, ageing [55]. Recently, strong linear and inverse associations of $\mathrm{VO}_{2}$ at $\mathrm{VT}$ (mean value $23.72 \pm 6.10 \mathrm{ml} \cdot \mathrm{kg}^{-1}$. $\mathrm{min}^{-1}$ ) with fatal cardiovascular and all-cause mortality outcomes in a general population has been shown [34]. In addition, $\mathrm{VO}_{2}$ at $\mathrm{VT}$ (mean (median) $=32.1(26.8-36.6)$ $\mathrm{ml} \cdot \mathrm{kg}^{-1} \cdot \mathrm{min}^{-1}$ ) was proved to have significant inverse relationship with arterial stiffness in adolescent boys, though magnitude of the associations is lower than that of maximal oxygen uptake [23]. Higher arterial stiffness in adults has been related to higher cardiovascular morbidity and mortality irrespective of well-known risk factors such as insulin resistance, hypertension, obesity and hyperlipidemia, [67]. We found oxygen uptake at ventilatory threshold to be $\sim 43 \mathrm{ml} \cdot \mathrm{kg}^{-1} \cdot \mathrm{min}^{-1}$ and $\sim 32 \mathrm{ml} \cdot \mathrm{kg}^{-1} \cdot \mathrm{min}^{-1}$ for basketball and control group, respectively. These are higher values then reported in [34] study and similar to results presented by [23], if the control group only is considered. The basketball group, in addition, is characterized by a much higher level of anaerobic threshold in comparison to both aforementioned studies. It is reasonable to ascribe those differences to the age and physical activity differences between studies, since [34] used middle aged males as subjects (42-61years), while [23] used healthy, untrained adolescents. Supporting our reasoning, it has been found that ventilatory threshold is more responsive to training than maximal oxygen consumption [41]. Taken all together, we can arguably assume that long term participation in recreational basketball seems to produce favorable aerobic capacity indices and consequently positively affects health status. We can speculate that engagement in regular basketball activity was most likely responsible for higher aerobic and lung parameter's levels in basketball group than controls. Indeed, basketball - specific activity pattern substantially tax aerobic capacity in order to sustain frequent bouts of high-intensity exercise [8], as phosphocreatine restoration aerobic energy system-dependent. In addition, $\mathrm{VO}_{2 \max }$ is significantly correlated to end-game repeated sprint test results, indicating its increasing importance during the final stage of the match [48]. Aerobic energy system is responsible for providing energy for all low-intensity movements during game, reported to represent around $65 \%$ of game active time [47]. Moreover, extensive utilization of aerobic metabolism during basketball was reported [54], with $\mathrm{VO}_{2 \max }$ significantly correlated to average oxygen consumption $(r=0.673 ; p<0.05)$ and the active time spent during play $(\mathrm{r}=0.962 ; \mathrm{p}<0.05)$. All the aforementioned indicate the importance of welldeveloped aerobic capacity in professional basketball as well as high aerobic demand during basketball games and practices which is likely responsible for high aerobic capacity of basketball-oriented participants in comparison to sedentary people found in our study.

Values of respiratory parameters found in our study are similar to ones obtained in a sample of professional team sport athletes. For example, one study reported VC, FEV1 and $\mathrm{FEV} 1 / \mathrm{VC}$ ratio to be $5.37 \mathrm{~L}, 4.59 \mathrm{~L}$ and $85.9 \%$, respectively in professional soccer players, almost identical to $6.01 \mathrm{~L}, 5 \mathrm{~L}$ and $83 \%$ obtained in a sample of 115 team sport athletes, including basketball players [16]. In addition, professional basketball players were reported to have $\mathrm{VC}$ of $5.8 \mathrm{~L}, \mathrm{FEV} 1$ of $4.9 \mathrm{~L}$ and FEV1/VC of $84.9 \%$ in [17] study, while another study [44] found basketball players to have $6.5 \mathrm{~L}, 5.48 \mathrm{~L}$ and $85.3 \%$ for VC, FEV1 and FEV1/ $\mathrm{VC}$, respectively. It should be noted that in the second study basketball players were attributed with dominant physique (body height of over $200 \mathrm{~cm}$ and body weight of over $91 \mathrm{~kg}$ ) which largely explain very high VC and FEV1 values. To the best of our knowledge, there are no reported data for recreational-basketball participants, so we consider our study findings an important addition to existing knowledge about the topic. Respiratory function is largely dependent on several non-modifiable factors such as hereditary pattern and ethnic background [64]. One's efficient breathing capacity has been proved to rely on other factors such as rib cage-width and strength of the respiratory muscles [64]. However, lung volumes of athletes greater than their sedentary counterparts has been repeatedly noted $[4,44]$ suggesting that regular exercise is determinant of lung function. For example, inspiratory muscle training performed at fixed resistance and ventilation rates comparable to ones obtained while conducting high intensity exercise [13], have been found to increase inspiratory muscle strength from $7-41 \%$ 
[49]. Numerous interventional investigations have also presented exercise-driven increases in pulmonary functions $[57,65]$. It has been theorized that heavy exercise-induced hyperventilation could induce airway smooth muscle tone and contractility reductions consequently leading to a decreased airway resistance and increased flow rates [59]. Repetitive smooth muscle elongation as a consequence of exercise - induced heavy breathing pattern is also hypothesized to reduce airway resistance. Taken all together, exercise training improves respiratory muscles strength and endurance, causes reduction in pulmonary resistance and increases lung elasticity. Therefore, well designed and regular exercise may be considered one of the most effective strategies one can do for oneself in prevention/treatment of respiratory conditions. Considering that even a small amount of high-intensity interval training was proved potent to develop maximal oxygen consumption [71] and lung function [14] it is plausible that intermittent activity - pattern during recreational basketball is "above threshold" intensity stimulus for lung parameters improvements, as we observed.

Our study findings are mostly in line with previously published interventional studies elaborating the influence of recreational - team sport engagement on various health - related outcomes in sedentary population. Indeed, previous team sport-studies, performed as small-sided games or full court game-like practices, have generally shown marked beneficial health effects in training-naive men and women [6]. For example, 12 weeks of soccer training [51] was found to produce significant increases in $\mathrm{VO}_{2 \max }$ relative to body weight $(24.2 \%$, ES $=1.20)$, with additional jump performance and flexibility beneficial effects in healthy untrained men $(\mathrm{n}=20,34 \pm 4$ years, $78.1 \pm 8.3 \mathrm{~kg}$, $179 \pm 4 \mathrm{~cm}$ ). Similar 12-week study results present significant improvements in maximal oxygen consumption in obese untrained adolescents conducting recreational soccer program consisting of 60 -min sessions performed 3 times/week [65]. In addition, Randers et al. [57] showed that 12 weeks of recreational basketball significantly increased $\mathrm{VO}_{2 \max }\left(2.4 \mathrm{ml} \cdot \mathrm{kg}^{-1} \cdot \mathrm{min}^{-1}\right)$, time to exhaustion $(47 \mathrm{~s})$, lean body mass $(0.8 \mathrm{~kg})$, and bone mineral density $\left(0.021 \mathrm{~g} / \mathrm{cm}^{2}\right)$ in healthy untrained men aged $(28.4 \pm 7.0$ years). Conducting recreational team handball training during 12 weeks has been shown to impose significant positive effects on physical performance and fitness attributes in untrained young women [27], although no improvements was observed for $\mathrm{VO}_{2 \text { peak }}$, a major lifestyle diseases-preventing parameter [9].

Despite the benefits observed, the study has several limitations. Firstly, a small sample size for both experimental and control group present important drawback in interpreting study results. Secondly, only young male participants were investigated with no females included. Thirdly, we compared recreational basketball with sedentary controls, while other conventional training programs could also be included. Studies to come should discuss the effects of recreational basketball in comparison to other conventional training programs such as running, concurrent training, gym-based cardio etc. Finally, further research is required to determine volume and frequency of recreational basketball suitable for long-term health benefits.

\section{Conclusions}

In conclusion, our results have indicated that chronic exposure to recreational basketball leads to adaptive changes in respiratory patterns (IVC and FEV1) and aerobic capacity (maximal oxygen consumption) in young male adults (university students). It seems that recreational basketball should be viewed as a part of future health enhancing strategies for this specific population. It will be interesting to observe future studies exploring same issues on different population groups as well as future interventional studies exploring relations of frequency and volume of recreational basketball and health-outcomes.

Conflict of interest: Authors state no conflict of interest.

\section{References}

1. Abdelkrim N.B., El Fazaa S., El Ati J. (2007) Timemotion analysis and physiological data of elite under19-year-old basketball players during competition. Br. J. Sports Med., 41: 69-75.

2. Andersen M.H., Ottesen L., Thing L.F. (2019) The social and psychological health outcomes of team sport participation in adults: An integrative review of research. Scand. J. Public Health, 47(8): 832-850.

3. Antero-Jacquemin J., Pohar-Perme M., Rey G., Toussaint J.F., Latouche A. (2018) The heart of the matter: years-saved from cardiovascular and cancer deaths in an elite athlete cohort with over a century of follow-up. Eur. J. Epidemiol., 33: 531-543.

4. Armour J., Donnelly P.M., Bye P.T. (1993) The large lungs of elite swimmers: an increased alveolar number? Eur. Respir. J., 6: 237-247.

5. Aspenes S.T., Nilsen T.I., Skaug E.A., Bertheussen G.F., Ellingsen Ø., Vatten L., Wisløff U. (2011) Peak oxygen uptake and cardiovascular risk factors in 4631 healthy women and men. Med. Sci. Sports Exerc., 43(8): 1465-1473.

6. Bangsbo J., Hansen P.R., Dvorak J., Krustrup P. (2015) Recreational football for disease prevention and treatment in untrained men: a narrative review examining cardiovascular health, lipid profile, body composition, muscle strength and functional capacity. Br. J. Sports Med., 49: 568-576. 
7. Bassett D.R., Howley E.T. (2000) Limiting factors for maximum oxygen uptake and determinants of endurance performance. Med. Sci. Sports Exerc., 32(1): 70-84.

8. Bishop D., Edge J., Goodman C. (2004) Muscle buffer capacity and aerobic fitness are associated with repeated-sprint ability in women. Eur. J. Appl. Physiol., 92: 540-547.

9. Blair S.N. (2009) Physical inactivity: the biggest public health problem of the 21 st century. Br. J. Sports Med., 43: $1-2$.

10. Castagna C., de Sousa M., Krustrup P., Kirkendall D.T. (2018) Recreational team sports: The motivational medicine. J. Sport Health Sci., 7: 129-131.

11. Castagna C., Impellizzeri F.M., Chaouachi A., Ben Abdelkrim N., Manzi V. (2011) Physiological responses to ball-drills in regional level male basketball players. J. Sports Sci., 29: 1329-1336.

12. Cohen J. (1988) The Concepts of Power Analysis. In Statistical power analysis for the behavioral sciences, 2nd Eds., Hillsdale: Lawrence Earlbaum Associates, NJ, pp. 1-18.

13. Downey A.E., Chenoweth L.M., Townsend D.K., Ranum J.D., Ferguson C.S., Harms C.A. (2007) Effects of inspiratory muscle training on exercise responses in normoxia and hypoxia. Respir. Physiol. Neurobiol., 156: 137-146.

14. Dunham C., Harms C.A. (2012) Effects of high-intensity interval training on pulmonary function. Eur. J. Appl. Physiol., 112(8): 3061-3068.

15. Duong M., Islam S., Rangarajan S. et al. (2019) Mortality and cardiovascular and respiratory morbidity in individuals with impaired FEV1 (PURE): an international, community-based cohort study. Lancet Glob. Health, 7(5): e613-e623.

16. Durmic T., Lazovic B., Djelic M., Suzic-Lazic J., Zikic D., Zugic V., Dekleva M., Mazic S. (2015) Sport-specific influences on respiratory patterns in elite athletes. J. Bras. Pneumol., 41(6): 516-522.

17. Durmic T., Lazovic-Popovic B., Zlatkovic-Svenda M., Djelic M., Zugic V., Gavrilovic T., Mihailovic Z., Zdravkovic M., Leischik R. (2017) The training type influence on male elite athletes' ventilatory function. BMJ Open Sport Exerc. Med., 3(1): e000240.

18. Edgett B.A., Ross J.E., Green A.E., MacMillan N.J., Milne K.J., Gurd B.J. (2013) The effects of recreational sport on $\mathrm{VO}_{2 \text { peak }}, \mathrm{VO}_{2}$ kinetics and submaximal exercise performance in males and females. Eur. J. Appl. Physiol., 113(1): 259-266.

19. Farid R., Azad F.J., Atri A.E., Rahimi M.B., Khaledan A., Talaei-Khoei M. (2005) Effect of aerobic exercise training on pulmonary function and tolerance of activity in asthmatic patients. Iran. J. Allergy Asthma Immunol., 4(3): 133-138.

20. Godfrey M.S., Jankowich M.D. (2016) The vital capacity is vital: epidemiology and clinical significance of the restrictive spirometry pattern. Chest., 149: 238-251.
21. Gore C.J. (2013) Determination of maximal oxygen consumption. In: Physiological Tests for Elite Athletes. 2nd ed., Tanner, R., Gore, C., Eds., Human Kinetics: Champaign, IL, pp. 103-122.

22. Guerra S., Carsin A.E., Keidel D. Sunyer J., Leynaert B., Janson C., Jarvis D., Stolz D., Rothe T., Pons M., Turk A., Anto J.M., Probst-Hensch N. (2017) Health-related quality of life and risk factors associated with spirometric restriction. Eur. Respir. J., 49(5): 1602096.

23. Haapala E.A., Laukkanen J.A., Takken T., Kujala U.M., Finni T. (2018) Peak oxygen uptake, ventilatory threshold, and arterial stiffness in adolescents. Eur. J. Appl. Physiol., 118(11): 2367-2376.

24. Hagberg J.M., Yerg II J.E., Seals D.R. (1988) Pulmonary function in young and older athletes and untrained men. J. Appl. Physiol., 65: 101-105.

25. Hill N.S., Jacoby C., Farber H.W. (1991) Effect of an endurance triathlon on pulmonary function. Med. Sci. Sports Exerc., 23: 1260-1264.

26. Hole D.J., Watt G.C., Davey-Smith G., Hart C.L., Gillis C.R., Hawthorne V.M. (1996) Impaired lung function and mortality risk in men and women: findings from the Renfrew and Paisley prospective population study. BMJ., 313: 711-715.

27. Hornstrup T., Wikman J.M., Fristrup B., Póvoas S., Helge E.W., Nielsen S.H., Helge J.W. Andersen J.L., Nybo L., Krustrup P. (2018) Fitness and health benefits of team handball training for young untrained women-A cross-disciplinary RCT on physiological adaptations and motivational aspects. J. Sport Health Sci., 7(2): 139-148.

28. Jurić I., Labor S., Plavec D., Labor M. (2019) Inspiratory muscle strength affects anaerobic endurance in professional athletes. Arh. Hig. Rada. Toksikol., 70(1): 42-48.

29. Kaminsky L.A., Arena R., Myers J. (2015) Reference Standards for Cardiorespiratory Fitness Measured With Cardiopulmonary Exercise Testing: Data from the Fitness Registry and the Importance of Exercise National Database. Mayo Clin. Proc., 90(11): 1515-1523.

30. Kannel W.B., Lew E., Hubert H.B., Castelli W.P. (1980) The value of measuring vital capacity for prognostic purposes. Trans. Assoc. Life Insur. Med. Dir. Am., 64: 66-83.

31. Kim J.Y., Yang Y., Sim Y.J. (2018) Effects of smoking and aerobic exercise on male college students'metabolic syndrome risk factors. J. Phys. Ther. Sci., 30(4): 595-600.

32. Kodama S., Saito K., Tanaka S., Maki M., Yachi Y., Asumi M., Sugawara A. Totsuka K., Shimano H., Ohashi Y., Yamada N., Sone H. (2009) Cardiorespiratory fitness as a quantitative predictor of all-cause mortality and cardiovascular events in healthy men and women: a meta-analysis. JAMA., 301: 2024-2035.

33. Koinis-Mitchell D., Kopel S.J., Seifer R., LeBourgeois M., McQuaid E.L., Esteban C.A., Boergers J. 
Nassau J., Farrow M., Fritz G.K., Klein R.B. (2017) Asthma-related lung function, sleep quality, and sleep duration in urban children. Sleep Health, 3: 148-156.

34. Kunutsor S.K., Kurl S., Khan H., Zaccardi F., Laukkanen J.A. (2017) Associations of cardiovascular and all-cause mortality events with oxygen uptake at ventilatory threshold. Int. J. Cardiol., 236: 444-450.

35. Kunutsor S.K., Kurl S., Laukkanen J.A. (2017) Association of oxygen uptake at ventilatory threshold with risk of incident hypertension: A long-term prospective cohort study. J. Hum. Hypertens., 31: 654-656.

36. Kwan M.Y., Cairney J., Faulkner G.E., Pullenavegum E.E. (2012) Physical activity and other health-risk behaviours during the transition into adulthood: A longitudinal cohort study. Am. J. Prev. Med., 42(1): 14-20.

37. Laine M.K., Kujala R., Eriksson J.G., Kautiainen H., Sarna S., Kujala U.M. (2017) Costs of diabetes medication among male former elite athletes in later life. Acta Diabetol., 54: 335-341.

38. Laukkanen J.A., Kurl S., Salonen R., Rauramaa R., Salonen J.T. (2004) The predictive value of cardiorespiratory fitness for cardiovascular events in men with various risk profiles: a prospective population-based cohort study. Eur. Heart J., 25: 1428-1437.

39. Laursen P.B., Jenkins D.G. (2002) The scientific basis for high-intensity interval training: optimising training programmes and maximising performance in highly trained endurance athletes. Sports Med., 32(1): 53-73.

40. Loe H., Rognmo Ø., Saltin B., Wisløff U. (2013) Aerobic Capacity Reference Data in 3816 Healthy Men and Women 20-90 Years. PLoS ONE, 8(5): e64319.

41. Mahon A.D., Vaccaro P.A.U.L. (1989) Ventilatory threshold and VO2max changes in children following endurance training. Med. Sci. Sports Exerc., 21(4): 425-431.

42. Mannino D.M., Ford E.S., Redd S.C. (2003) Obstructive and restrictive lung disease and functional limitation: data from the Third National Health and Nutrition Examination. J. Intern. Med., 254: 540-547.

43. Martin B.J., Stager J.M. (1981) Ventilatory endurance in athletes and non-athletes. Med. Sci. Sports Exerc., 13: 21.

44. Mazic S., Lazovic B., Djelic M., Suzic-Lazic J., Djordjevic-Saranovic S. Durmic T., Soldatovic I., Zikic D., Gluvic Z., Zugic V. (2015) Respiratory parameters in elite athletes-does sport have an influence? Rev. Port. Pneumol., 21(4): 192-197.

45. Mc Claren S.R., Babcock M.A., Pegelow D.F., Reddan W.G., Dempsey J.A. (1995) Longitudinal effects of aging on lung function at rest and exercise in healthy active fit elderly adults. J. Appl. Physiol., 78: 1957-1968.

46. Mc Connell A.K., Caine M.P., Sharpe G.R. (1997) Inspiratory muscle fatigue following running to volitional fatigue: the influence of baseline strength. Int. J. Sports Med., 18: 169-173.
47. Mc Innes S.E., Carlson J.S., Jones C.J., McKenna M.J. (1995) The physiological load imposed on basketball players during competition. J. Sports Sci., 13: 387-397.

48. Meckel Y., Gottlieb R., Eliakim A. (2009) Repeated sprint tests in young basketball players at different game stages. Eur. J. Appl. Physiol., 107: 273-279.

49. Mickleborough T.D., Stager J.M., Chatham K., Lindley M.R., Ionescu A.A. (2008) Pulmonary adaptations to swim and inspiratory muscle training. Eur. J. Appl. Physiol., 103(6): 635-646.

50. Middleton K.R., Anton S.D., Perri M.G. (2013) Longterm adherence to health behavior change. Am. J. Lifestyle Med., 7: 395-404.

51. Milanović Z., Pantelić S., Sporiš G., Mohr M., Krustrup P. (2015) Health-Related Physical Fitness in Healthy Untrained Men: Effects on $\mathrm{VO}_{2 \max }$, Jump Performance and Flexibility of Soccer and Moderate-Intensity Continuous Running. PLoS One, 10(8): e0135319.

52. Montgomery P.G., Pyne D.B., Minahan C.L. (2010) The physical and physiological demands of basketball training and competition. Int. J. Sports Physiol. Perform., 5: 75-86.

53. Myers J., Prakash M., Froelicher V., Do D., Partington S., Atwood J.E. (2002) Exercise capacity and mortality among men referred for exercise testing. N. Engl. J. Med., 346: 793-801.

54. Narazaki K., Berg K., Stergiou N., Chen B. (2009) Physiological demands of competitive basketball. Scand. J. Med. Sci. Sports., 19: 425-432.

55. Poole D.C., Rossiter H.B., Brooks G.A., Gladden L.B. (2020) The anaerobic threshold: $50+$ years of controversy. J. Physiol., 28: DOI: 10.1113/JP279963. Epub ahead of print.

56. Rakesh T., Varghese C.A. (2019) Linkage of aerobic capacity and body fat percent: Effects of recreational activity on aerobic capacity, body composition, blood pressure and resting heart rate in University students. Med. Sci., 23(98): 557-564.

57. Randers M.B., Hagman M., Brix J. Christensen J.F., Pedersen M.T., Nielsen J.J., Krustrup P. (2018) Effects of 3 months of full-court and half-court street basketball training on health profile in untrained men. J. Sport Health Sci., 7: 132-138.

58. Robinson E.P., Kjeldgaard J.M. (1982) Improvement in ventilatory muscle function with running. J. Appl. Physiol., 52: 1400-1406.

59. Scichilone N., Morici G., Marchese R., Bonanno A., Profita M., Togias A., Bonsignore M.R. (2005) Reduced airway responsiveness in nonelite runners. Med. Sci. Sports Exerc., 37(12): 2019-2025.

60. Sigmundova D., Chmelik F., Sigmund E., Feltlova D., Fromel K. (2013) Physical activity in the lifestyle of Czech university students: Meeting health recommendations. Eur. J. Sport. Sci., 13(6): 744-750. 
61. Stojanović E., Stojiljković N., Scanlan A.T. Dalbo V.J., Berkelmans D.M., Milanović Z. (2018) The Activity Demands and Physiological Responses Encountered During Basketball Match-Play: A Systematic Review. Sports Med., 48: 111-135.

62. Stojanović E., Stojiljković N., Stanković R., Scanlan A.T., Dalbo V.J, Milanović Z. (2019) Recreational basketball small-sided games elicit high-intensity exercise with low perceptual demand. J. Strength Cond. Res., DOI: $10.1519 /$ JSC.0000000000003306. Online ahead of print.

63. Swift D.L., Lavie C.J., Johannsen N.M. (2013) Physical activity, cardio-respiratory fitness, and exercise training in primary and secondary coronary prevention. Circ. J., 77(2): 281-292.

64. Tülin A., Pelin A., Mehmet Ç. (2012) Comparison of respiratory functions of athletes engaged in different sports branches. TJSE., 14: 76-81.

65. Vasconcellos F., Seabra A., Cunha F., Montenegro R., Penha J., Bouskela E. et al. (2016) Health markers in obese adolescents improved by a 12 -week recreational soccer program: a randomised controlled trial. J. Sports Sci., 34: 564-575.

66. Vitaić S., Erceg M., Milić M. (2015) Differences in Pulmonary Ventilation Function Parameters in Young Volleyball Players According to Competitive Success Criterion. Res. Phys. Edu. Sport Health, 4: 113-117.

67. Vlachopoulos C., Aznaouridis K., Stefanadis C. (2010) Prediction of cardiovascular events and all cause mortality with arterial stiffness. A systematic review and metaanalysis. J. Am. Coll. Cardiol., 55: 1318-1327.

68. Volianitis S., McConnell A.K., Koutedakis Y., McNaughton L., Backx K., Jones D.A. (2001) Inspiratory muscle training improves rowing performance. Med. Sci. Sports Exerc., 33: 803-809.

69. Wang C.Y., Haskell W.L., Farrell S.W., LaMonte M.J., Blair S.N., Curtin L.R., Hughes J.P., Burt V.L. (2010) Cardiorespiratory fitness levels among US adults 20-49 years of age: findings from the 1999-2004 National Health and Nutrition Examination Survey. Am. J. Epidemiol., 171(4): 426-435.

70. Wasserman K., Whipp B.J., Koyal S.N., Beawer W.L. (1973) Anaerobic threshold and respiratory gas exchange during exercise. J. Appl. Physiol., 35: 236-243.

71. Weston M., Taylor K.L., Batterham A.M., Hopkins W.G. (2014) Effects of low-volume high-intensity interval training (HIT) on fitness in adults: a meta-analysis of controlled and non-controlled trials. Sports Med., 44(7): 1005-1007.

72. Ziv G., Lidor R. (2009) Physical attributes, physiological characteristics, on-court performances and nutritional strategies of female and male basketball players. Sports Med., 39(7): 547-568.

\section{Received 14.12.2020 \\ Accepted 09.02.2021}

(C) University of Physical Education, Warsaw, Poland

Acknowledgments

Supported by the Serbian Ministry of Education, Science and Technological Development (179011) and Provincial Secretariat for Higher Education and Scientific Research (142-451-2094). 